\title{
THE EFFICACY OF LACTOBACILLUS ACIDOPHILUS AND/OR DICLAZURIL FOR INHIBITION AND CONTROL OF EIMERIA TENELLA INFECTION IN BALADY CHICKS
}

\author{
El-Dakhly, Kh. M. ; Azza A. El-Sawah ${ }^{* *}$; Shalaby, A. A. ${ }^{* * *}$ and El-Nesr, Kh. \\ $A .^{* * *}$ \\ * Department of Parasitology, Fac. of Vet. Med. Beni-Suef Univ. \\ ** Department of Poultry Diseases, Fac. of Vet. Med. Beni-Suef Univ. \\ *** Department of Pathology, Fac. of Vet. Med. Beni-Suef Univ.
}

\begin{abstract}
This study was carried out on one hundred and twenty 14-day old Fayomi chicks in 6 groups(20 each)to detect efficacy of L. acidophilus (as a natural immunopotentiator), Diclazuril (anti-coccidial drug) or both against E. tenella infection. Five groups were experimentally infected, at the age of 14-days, with E. tenella in a dose of $2 \times 10^{4}$ oocysts/bird; among those one group was given Diclazuril in a curative dose, another group was given the same drug in a prophylactic dose, a third group was given L. acidophilus, a fourth group was given both L. acidophilus and Diclazuril in prophylactic doses. The other two groups were kept as control infected non-medicated and control negative (non-infected, non-medicated). Number of shedding oocycts in drooping, changes in body weight gain, lesion scores of the necropsied birds and histopathological findings were used to evaluate the efficacy of both therapeutics. Comparing the obtained results showed that: the best values were seen in the group given both $L$. acidophilus and Diclazuril followed by those groups given $L$. acidophilus only then the group given Diclazuril alone. The medicated groups were given better results than non-treated infected one. This revealed a distinct anti-coccidial effect of $L$. acidophilus and this provides a further insight to the antagonistic property of $L$.
\end{abstract}


acidophilus and other natural microflora against infection with intestinal protozoa.

\section{INTRODUCTION}

Coccidiosis is a disease resulting from infection with Eimerial spec-ies. Eimeria tenella is one of the most significant obligate intracellular protozoa affecting the caecal epithelia of domestic fowls. Infection and developmental stages of the parasite are clinically manifested by bloody mucoid drooping, loss of general health conditions and variable mortality resulting from invasion of massive number of infective and replicative stages of parasite which ended by several economic consequences (Yun et al., 2000).

For controlling of this disease, effective therapeutics must be given especially those originated from new chemical components and showed successful anti-coccidial effect for infected host. Diclazuril is a synthetic form of benzene-acetonitrile compounds. This drug was to be effective against all pathogenic species of Eimeria infecting poultry (Conway et al., 2002).

Despite,using of anticoccidial drugs may result in clinical failure and the occurrence of some resistant Eimeria strains and this has encouraged the need to alternative therapeutic strategies which have included the use of some probiotic microorganisms that provide health benefits to the host by antagonizing pathogens and modulating both innate and acquired immunity at local and systemic levels (Champan, 1998 and Isolauri et al., 2001).

Among those, gut microflora play an important role in both health and disease conditions; and in practice they play a role in host protection against colonization of several pathogens(Kasper,1998 and McCracken and Lorenz, 2001). The protective role of these microflora is due to their non-specific barrier effects (steric interference), competition of intestinal surface sites, production of anti-pathogenic products, enhancement of 
immune response or a combination of all (Tierney et al., 2004). The probiotic, Lactobacillus species (Reid, 1999 and Vaughan et al., 1999) were used; mainly L. acidophilus colonize the gastrointestinal tract of chickens and exhibit an intestinal site specificity (Jin et al., 1996 and Gusils et al., 1999). L. acidophilus has shown to influence the parasitic infection (Alak et al., 1999; Waters et al., 1999; Singer and Nash, 2000 and Dalloul et al., 2003).

The objective of this study was to investigate the anti-parasitic effects of L. acidophilus alone or with Diclazuril against experimental infection of balady chicks with E. tenella.

\section{MATERIALS AND METHODS}

\section{Rearing of chicks:}

One hundred and sixty one-day old Fayomi chicks were obtained from El-Azab project and bred on clean disinfected wire floor pens. These chicks were allowed to drink clean adequate water and feed ad libitum on commercial non-medicated broiler starter ration containing 21 $\%$ crude proteins. All chicks were kept in these conditions from the first day till the $14^{\text {th }}$ day of age (Ali et al., 2002).

Strict hygienic measures were applied,as well as vaccination against Newcastle disease by Hitchner B1 strain using eye drop method at the $7^{\text {th }}$ day of age. One hunched \& twenty of 14-days old were chosen for the experiments.

\section{Preparation of E. tenella sporulated oocysts:}

Oocysts of E. tenella were obtained from the intestines of naturally infected chickens, separated by using sieving and sedimentation techniques (Soulsby, 1978). These oocysts were put in $2.5 \%$ potassium dichromate solution (1 part fecal samples / 2 parts of the solution) for sporulation in a room temperature for 24 hours. Thus, the resulted sporulated oocysts 
were counted by using McMaster technique (Soulsby, 1978) to be used for infection of chicken groups in a dose of $2 \times 10^{4}$ oocysts/bird per os (Dalloul et al., 2003 and Mosshira et al., 2003).

\section{Using of Diclazuril formulation:}

In the experiment, we used a commercial available Diclazuril (Dizacox ${ }^{\circledR}$ which is obtained from Jordan Vet. and Agr. Med. Ind. Co., Jovet-Batch No.050508, supplied from Prof. Dr. Amer, Dept. of Poultry diseases Fac. Vet. Med., Cairo Univ.).

\section{Culturing of Lactobacillus acidophilus:}

Frozen suspensions of $L$. acidophilus were thawed and reactivated in MRS broth before the study. The bacteria were subcultured in MRS broth anaerobically for 48 hours at $37^{\circ} \mathrm{C}$ and harvested by centrifugation at $10000 \mathrm{rpm}$ for $10 \mathrm{~min}$. concentrated suspensions were frozen at -80 ${ }^{\circ} \mathrm{C}$ with $10 \%$ glycerol (vol./vol.) till use. Prior to experimentation, bacterial counts were determined by plat count on MRS agar (Tierney et al., 2004 and Martin et al., 2005). L. acidophilus was given in a dose of 1 x $10^{8} \mathrm{CFU} / \mathrm{ml} /$ bird.

\section{Experimental design:}

One hundred and twenty 14-day old Fayomi chicks were weighted and divided into 6 equal groups as follow:

Group (1): Non-infected non-treated group (control negative).

Group (2): E. tenella infected non-treated group (infected control).

Group (3): Group treated with Diclazuril at a dose of $1 \mathrm{ml} / 4$ liter drinking water for 2 successive days, at the $5^{\text {th }}$ day post-infection as (the bloody drooping was seen).

Group (4): Group given Diclazuril in a prophylactic dose of $1 \mathrm{ml} / 8$ litre in drinking water(half the therapeutic dose)7 days before the infection with E. tenella. 
Group (5): Group given L.acidophilus in a dose of $1 \mathrm{X} 10^{8} \mathrm{CFU} / \mathrm{ml} / \mathrm{bird}$ in drinking water 7 days before infection.(Martin et al.,2005).

Group (6): Group given both L. acidophilus and Diclazuril via drinking water in similar prophylactic doses at 7 days before the infection; respectively.

\section{Parameters of evaluation:}

\section{1- Counting of the shedding oocysts:}

Fecal samples were examined daily just after detection of $1^{\text {st }}$ signs (bloody drooping) at the $5^{\text {th }}$ day post infection till the $7^{\text {th }}$ day. Counting of the shedding oocysts in all infected groups were estimated in average values (Liou et al., 2001).

\section{2- Changes in body weight gain:}

At the $7^{\text {th }}$ day post infection,all chicks were re-weighted,necropsied and alterations in body weights were calculated according to the following equation (Samar, 1991) as shown in Table (3):

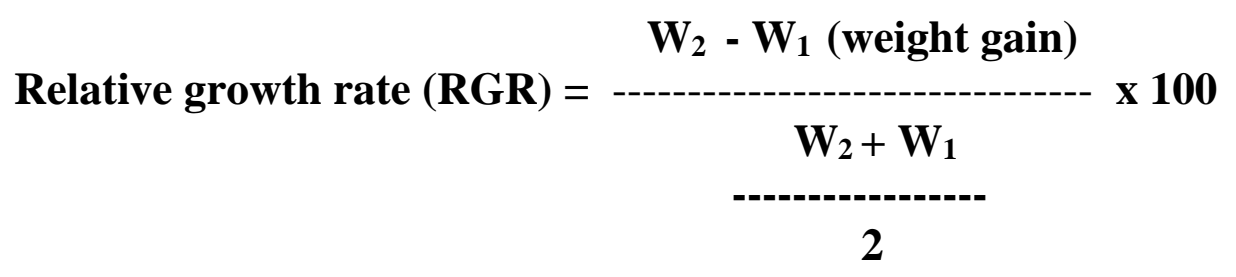

Where $\mathbf{W}_{\mathbf{1}}=$ Average initial weight of birds in each group before infection (zero day of infection).

$\mathbf{W}_{2}=$ Average final weight at the $7^{\text {th }}$ post infection .

\section{3- Lesion score:}

Gross lesions in the caeci of infected chicks were taken as criterion to detect severity of infection in medicated groups to be compared with those of non-medicated ones, according to Johnson and Reid,(1970) and Conway (1979). The calculated lesion scores are shown in Table (2).

\section{4- Histopathology:}


For histopathological study, at the $7^{\text {th }}$ day post infection, about $1 \mathrm{~cm}$ of caecal tissue specimens were taken from all birds, fixed in 10\% neutral formalin, then these specimens were thoroughly washed, dehydrated in ascending concentrations of ethyl alcohol, followed by clearing in xylol and finally embedded in paraffin according to Bancroft and Stevens, (1996). 4-5 $\mu \mathrm{m}$ thick paraffin sections were stained with routine Hematoxylin and Eosin, and examined microscopically.

\section{RESULTS}

Table (1): Differentiation in number of the shedding Eimeria tenella oocysts/ gm droopings of the challenged groups.

\begin{tabular}{|c|c||c|c|c|c||}
\hline \multicolumn{1}{|c|}{ Group } & \multirow{2}{*}{ Group (2) } & Group (3) & Group (4) & Group (5) & Group (6) \\
\hline \hline $\mathbf{5}^{\text {th }}$ & 103000 & 12000 & 15000 & 17000 & 9000 \\
\hline $\mathbf{6}^{\text {th }}$ & 774000 & 50000 & 16000 & 2000 & 1000 \\
\cline { 2 - 6 } & 260000 & 61000 & 17000 & 9000 & 1000 \\
\hline $7^{\text {th }}$ & $\mathbf{1 1 3 7 0 0 0}$ & $\mathbf{1 2 3 0 0 0}$ & $\mathbf{4 8 0 0 0}$ & $\mathbf{2 8 0 0 0}$ & $\mathbf{1 1 0 0 0}$ \\
\hline \hline Sum & $\mathbf{3 7 9 0 0 0}$ & $\mathbf{4 1 0 0 0}$ & $\mathbf{1 6 0 0 0}$ & $\mathbf{9 3 0 0}$ & $\mathbf{3 6 5 0}$ \\
\hline
\end{tabular}

Results of Table (1) showed that, the lowest number of shedding oocysts was in the $6^{\text {th }}$ group that given both L.acidophilus and Diclazuril followed by that of the $5^{\text {th }}$ group that medicated with Lactobacillus alone, while both the $3^{\text {rd }}$ and the $4^{\text {th }}$ groups showed a higher number of the shedding oocysts compared with the groups given Lactobacillus. The control infected non-medicated group showed the highest number of the shedding oocysts throughout the experiment.

These findings were parallel to the clinical signs appeared on the infected birds of all groups; where the $6^{\text {th }}$ group that given(L.acidophilus and Diclazuril) showed somewhat normal fecal contents with very little $\overline{\text { Kafr El-Sheikh Vet. Med. J. Vol. } 4 \text { No. } 1 \text { (2006) }}$ 
amount of blood, these signs are more or less distinct in the group given Lactobacillus alone. These signs showed slight increase in both groups given Diclazuril either in prophylactic or in curative doses, and the most obvious clinical sings represented by severe bloody diarrhea, emaciation, off food and general depression are found in the challenged non-treated group.

Table (2): Differences in lesion scores of all chicks groups.

\begin{tabular}{|c||c|c|c|c||c|}
\hline \multirow{2}{*}{$\begin{array}{c}\text { Group } \\
\text { number }\end{array}$} & \multicolumn{4}{|c||}{ Lesion score } & \multirow{2}{*}{$\begin{array}{c}\text { Mean Lesion } \\
\text { Scores }\end{array}$} \\
\cline { 2 - 6 } & grade (1) & grade (2) & grade (3) & grade (4) & \\
\hline \hline \multirow{2}{*}{ Group (1) } & - & - & - & - & 0 \\
\hline Group (2) & - & - & 1 & 19 & 3.95 \\
\hline Group (3) & - & 9 & 11 & - & 2.55 \\
\hline Group (4) & 1 & 6 & 13 & - & 2.60 \\
\hline Group (5) & 5 & 8 & 7 & - & 2.10 \\
\hline Group (6) & 11 & 4 & 5 & - & 1.70 \\
\hline
\end{tabular}

\section{where:}

$$
\begin{aligned}
& \text { grade }(0) \longrightarrow \text { no lesion } \\
& \text { grade }(1) \longrightarrow \text { very mild changes } \\
& \text { grade }(2) \longrightarrow \text { mild changes } \\
& \text { grade }(3) \longrightarrow \text { moderate changes } \\
& \text { grade }(4) \longrightarrow \text { severe changes }
\end{aligned}
$$

Chicks in all groups were subjected to post-mortem examination (Figs.1-6) as well as lesion score was recorded (Table 2) and it was classified into four stages as follows:

1) There are very few scattered petechiae on the caecal wall, with no visible thickening. Normal caecal contents are present. 
2) Lesions are more numerous with noticeable blood in the caecal contents. Caecal contents are present.

3) Large amounts of blood or caecal cores are present. Caecal wall is greatly thickened. Little fecal contents, if any, are present in the caeca.

4) Caecal pouches either contain blood or large caseous cores. The caeca were greatly distended. Birds die from Eimeria tenella are scored as a grade (4).

Table (3):Differentiation in values of Relative Growth Rate(RGR)in all groups of experimented chicks.

\begin{tabular}{|c||c||c||c|c||c||c|}
\hline Item & Group (1) & Group (2) & Group (3) & Group (4) & Group (5) & Group (6) \\
\hline \hline $\mathbf{W}_{\mathbf{1}}$ (average)/gm & 98 & 86.5 & 103 & 101.5 & 99 & 100 \\
\hline $\mathbf{W}_{\mathbf{2}}$ (average)/gm & 205 & 125.5 & 153 & 156 & 151 & 175 \\
\hline $\mathbf{W}_{\mathbf{2}}-\mathbf{W}_{\mathbf{1}}$ (gain) & 107 & 39 & 50 & 54.5 & 52 & 75 \\
\hline $\mathbf{W}_{\mathbf{2}}+\mathbf{W}_{\mathbf{1}}$ & 303 & 212 & 253 & 257.5 & 250 & 275 \\
\hline RGR & 71 & 37 & 39 & 42 & 42 & 55 \\
\hline
\end{tabular}

W1 average weight of each group at the zero day of challenge.

W2 average weight of each group at the $7^{\text {th }}$ day post challenge (the end of the experiment).

Our results revealed that the highest value of RGR was found in the control non-infected and non-treated group while the lowest value was in the control infected non-treated group. Moreover, groups given Lactobacillus either alone or mixed with Diclazuril showed higher values than that given Diclazuril alone.

\section{Histopathological findings:}

In group(1),non-infected and non-treated group,all cases showed no microscopic changes (Fig.7).

In group (2), E.tenella infected non-treated group,the microscopical examination revealed that the caecal lumens of all birds were markedly distended with hemorrhagic cores(Fig.8), which composed of heamolysed erythrocytes, desquamated epithelial cells, and coccidial stages, as well Kafr El-Sheikh Vet. Med. J. Vol. 4 No. 1 (2006) 
as large number of leucocytes (Fig.9). The surface epithelium showed severe degeneration and necrosis in different degrees. Complete destruction of caecal mucosa was detected in some cases.Coccidial stages were demonstrated in degenerated epithelial cells of crypts and villi.Extensive tissue damage was found in the caecai of some birds.In all cases,the submucosa was massively infiltrated with mononuclear cells(lymphocytes and macrophages) with or without heterophils. Muscularis mucosa was destructed in some areas. Focal leucocytic infiltration was obvious in the muscular layer.

In group(3)treated chicks with Diclazuril after infection, hemorrhagic cores were moderately detected in the cecal lumens of 9 cases.Degenerated and necrosed epithelial cells, coccidial stages, and erythrocytes were the main contents of the cores. The mucosal epithelium was severely affected in 10 chicks and the inflammatory reaction was obvious in those cases. Coccidial stages were found in the villi and crypts of 8 cases (Fig.10).

The submucosa was severely infiltrated with mononuclear and mildly with heterophils, 10 and 5 birds,respectively.In 7 cases,the muscular layer was infiltrated with leucocytes in different degrees.

In group (4), treated with Diclazuril before the infection with $E$. Tenella, the intestine of 8 birds was distended with hemorrhagic core moderatley, which comprised desquamated epithelial cells, coccidial stages, and mononuclear cells. The mucosa was degenerated and necrosed in 10 cases. Extensive tissue damage was found in few cases. Coccidial stages were demonstrated in 8 birds. The submucosa was infiltrated with mononuclear cells and heterophils in 10 and 7 cases, respectively. The muscularis mucosa and muscular layer were focally infiltrated with mononuclear cells (Fig. 11) in 5 birds.

In group (5), given Lactobacillus acidophilus before infection, the intestinal lumens were moderately distended with exudates 2cases and ceacal cores were not detected. This exudate consisted of degenerated and necrosed epithelial cells with few coccidial stages. The surface epithelium showed mild degree of degeneration and necrosis in 8cases with the presence of coccidial stages in the villi 7cases. Moderately, the 
submucosa was focally or diffusely infiltrated with mononuclear cells with or without heterophils. Focal leucocytic infiltration was seen in the muscualar layer of 4 cases.

In group(6)given both L.acidophilus and Diclazuril in a prophylactic dose before the infection,the intestinal core was only recorded in one case and it was minimal. Its component was most commonly desquamated epithelial cells. The mucosa showed very mild degree of degeneration (Fig.12) with the presence of coccidial stages in the villi. Mononuclars and heterophils infiltrated the submucosa.

\section{DISCUSSION}

In our study, we tried to spotlight on the inhibition and control of $E$. tenella infection mainly by using $L$ acidophilus and comparing this effect with that of Diclazuril to evaluate its effectiveness as anticoccidial activity.

Non-medicated infected birds showed anorexia, depression and severe haemorrhage in their drooping and vent during the period of 5-7 days post infection, also body weight gain and consequently relative growth rate $(\mathrm{RGR}=37)$ were greatly reduced in this group. This reduction is the major contributor to the loss of production accompanying coccidial infection in young chicks as inflammatory reactions divert energy from growth which may affect the weight gain (Klasing et al., 1987 and Moshira et al.,2003).Moreover,the oocycts output in this group was greatly increased as associated with heavy lesion scores (3 - 4) mean lesion score (3.95).

In L. acidophilus group, the general health conditions were greatly improved and this was accompanied with reduced number of shedding oocysts, improved body weight gain, and relative growth rate $(R G R=42)$ as well as less lesion scores(mean lesion score 2.10).These improvements might be due to the anti-parasitic nature of L.acidophilus which constitute the most essential type of microflora present along the intestine as it produces hydrogen peroxide and some organic acids as lactic acid; the latter leads to lowering $\mathrm{pH}$ in the intestine (Radwan and Hassan, 2004) 
keeping the medium is unsuitable for the growth of several pathogens including the protozoa, and this explain the anticoccidial property through which it able to adhere to the enterocytes in order to exclude or reduce the protozoal adherence; moreover, this leads to modulation of the immune response, not only the innate defense mechanism, but also both cellmediated and acquired humoral immune responses. These results are in agreement with results obtained by Jin et al., (1996); Bernet-Camard et al., (1997); Isolauri et al., (2001); Moshira et al., 2003; Tierney, (2004) and Martin et al., (2005).

The group medicated with Lacobacillus and Diclazuril showed lesion score (1-2-3) with mean lesion score (1.70). Also, the general health conditions were greatly improved with reduced number of the shedding oocysts associated with improved body weigh gain and relative growth rate $(\mathrm{RGR}=55)$.

Concerning the pathological studies, the severity of infection varied among different groups. Cecal cores were markedly observed in the infected non-medicated group. While, the medicated group either with $L$. acidophilus or With L.acidophilus and Diclazuril before infection,showed mild gross and histopathological changes. This indicated that the intestinal lesions were diminished in the chicks treated with Lactobacillus alone or Lactobacillus and Diclazuril before infection compared with other groups. Our results were in a great accordance with the parasitological resultes, the presence of oocysts, macrogamets and microgamets was reduced in examined fecal samples and with the results reported by Dalloul et al., (2005).

All these improvements are augmented when L.acidophilus was used together with Diclazuril which induced a marked ceasing in the developmental cycle and inhibition of all developmental stages of Eimeria tenella 
(Kawazone and Fabio, 1994 and El-Banna et al., 2005). Moreover, results of $L$. acidophilus treatments were somewhat better than those obtained by prophylactic usage of Diclazuril alone and this encourages the using of L. acidophilus on the basis that it is one of the natural gut microflora (Upcroft and Upcroft, 2001).

We can concluded that, the natural microflora of poultry is an ideal reservoir of $L$. acidophilus which is a probiotic organism can be extended in the future to include alternative strategy that may contribute to the prevention and control of coccidiosis and other parasitic infections.

\section{FIGURES}

Fig. (1): Caecum of infected chick showing severe caecal core formation.

Fig. (2): Caecum of Diclazuril treated chick post challenge showing moderate caecal core formation.

Fig. (3): caecum of Diclazuril treated chick before infection showing moderate enlargement of the cecum.

Fig.(4): caecum of Lactobacillus treated chick pre-challenge showing mild enlargement of the cecum .

Fig.(5): Caecum of Lactobacillus and Diclazuril treated chick pre-challenge showing very mild cecal enlrgment.

Fig.(6): Normal caecum of a negative control chick.

Fig.(7): Caecum of a negative control chick showing normal histological structure. (H\&E-X100).

Fig.(8): Caecum of Eimeria tenella infected chick showing hemorrhagic core. (H\&E-X40). 
Fig.(9): Caecal core of Eimeria tenella infected chick containing erytherocytes, degenertated epithelial cells , coccidial stages, and leucocytes. H\&EX200.

Fig.(10): Caecum of chick treated with Diclazuril post challenge showing coccidial stages in the epithelial cell of villi and crypts. H\&E-X400.

Fig.(11): Caecum of chick treated with Diclazuril pre-challenge showing leucocytic infiltration of submucosa and muscularis mucosa (H\&E$\mathrm{X} 100)$.

Fig. (12): Caeceum of chick given Diclazuril and Lactobacillus pre-challenge showing very mild degeneration of the surface epithelium. H\&EX100. 
The Efficacy Of Lactobacillus Acidophilus And/Or Diclazuril ...

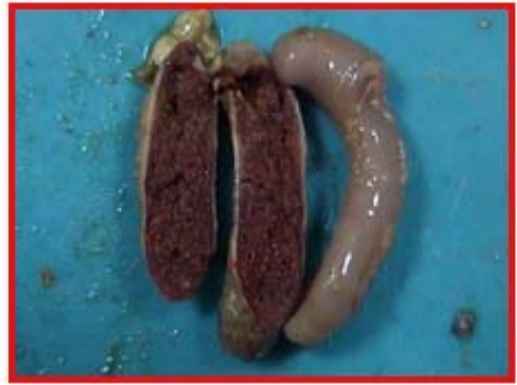

Fig.1

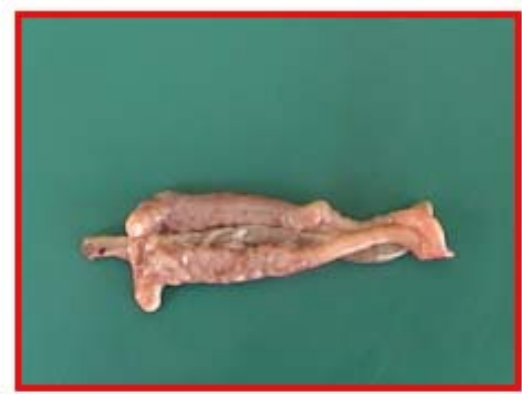

Fig.3

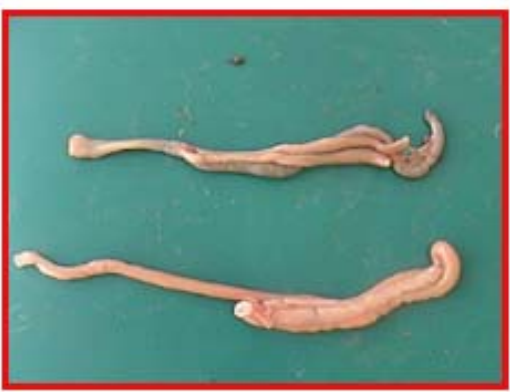

Fig.5

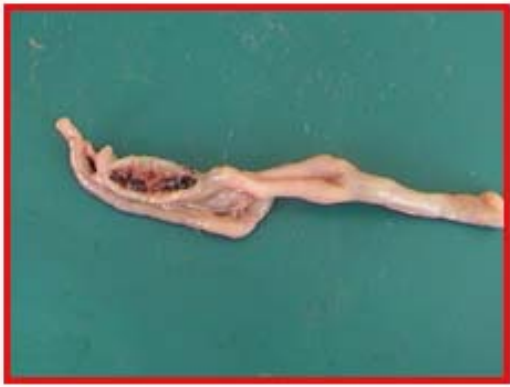

Fig.2

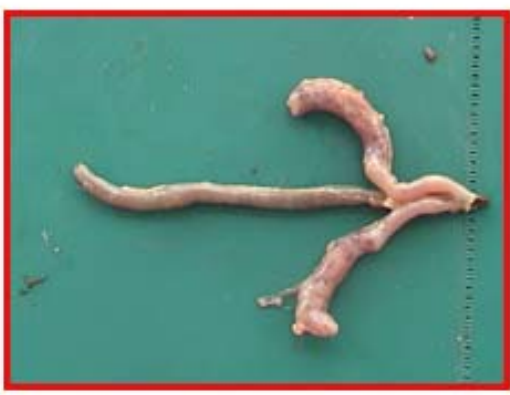

Fig.4

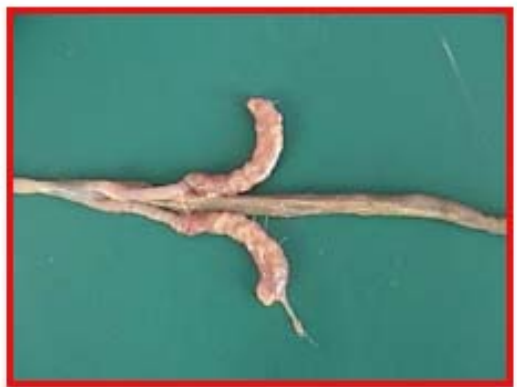

Fig.6

$\overline{\text { Kafr El-Sheikh Vet. Med. J. Vol. } 4 \text { No. } 1 \text { (2006) }}$ 


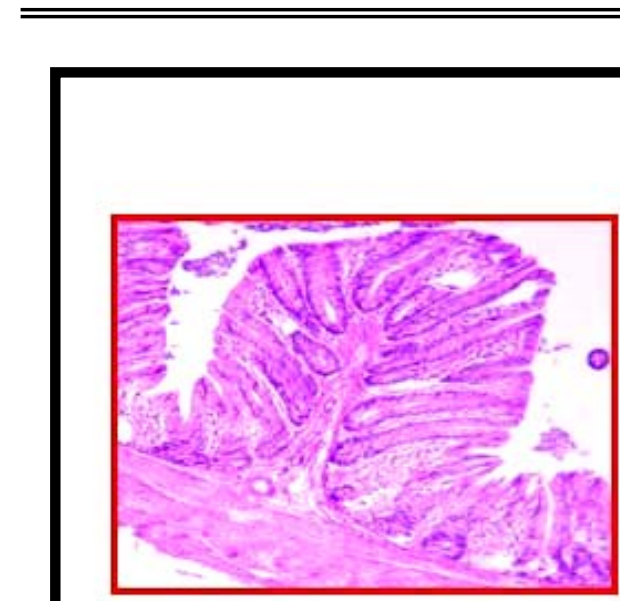

Fig.7

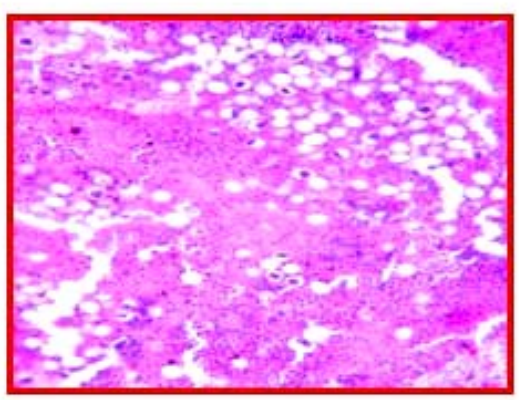

Fig.9

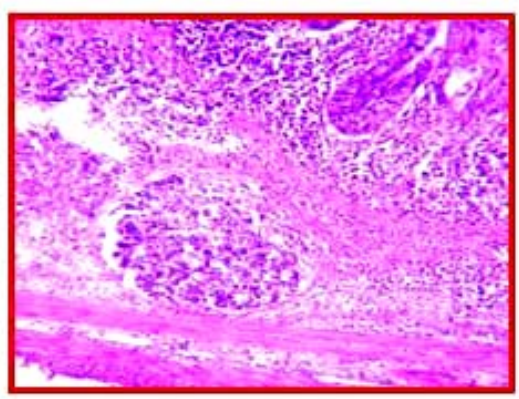

Fig.11

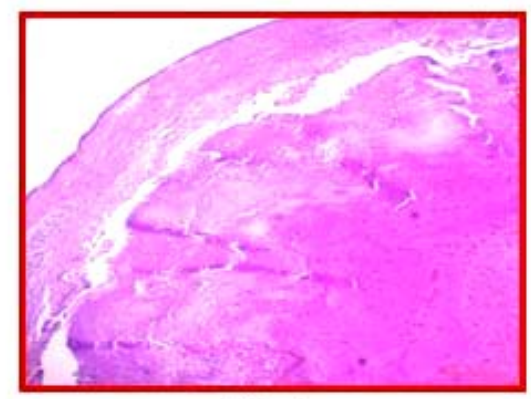

Fig.8

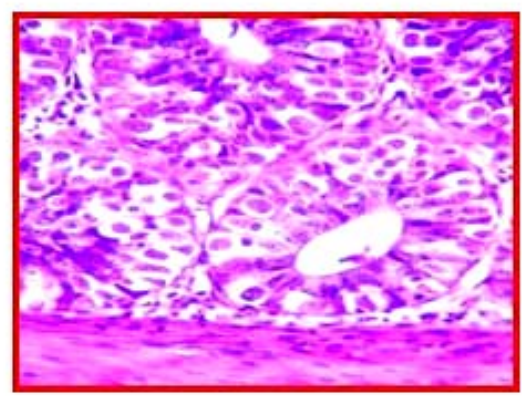

Fig.10

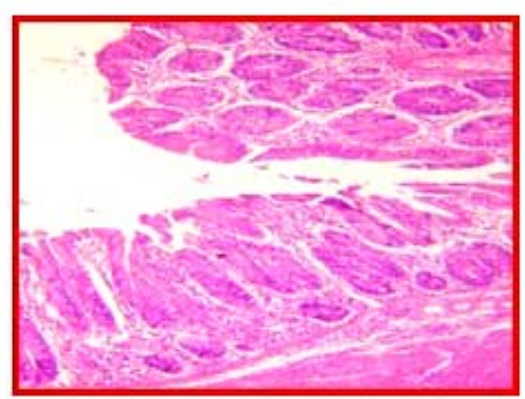

Fig12

$\overline{\text { Kafr El-Sheikh Vet. Med. J. Vol. } 4 \text { No. } 1 \text { (2006) }}$ 


\section{REFERENCES}

- Alak, J. I.; Wolf, B. W.; Mdurvwa, E. G.; Pimentel-Smith, G. E.; Kolavala, S.; Abdel-Rahman, $H$. and Suppiramanian, $V$. (1999): Supplementation with Lactobacillus reuteri or $L$. acidophilus reduced intestinal shedding of Cryptosporidium parvum oocysts in immunode-ficient C57BL/mice. Cell. Mol. Biol., 45: 855 - 863.

- Ali, M. A.; Elham A. El-Ebiary and Nassif, S. A. (2002): Studies on sensitivity of coccidiosis vaccine starins to anticoccidial drugs.J.Egypt. Vet. Med. Ass., 62 (5): 101 - 106.

- Bancroft, J. and Stevens, A. (1996): Theory and practice of histolog-ical techniques. $4^{\text {th }}$ ed. Chukhll Living Stone, New York.

- Bernet-Camard,M.; Lievin, V.; Neeser, R.; Servin, A. and Hudalt, S. (1997): The human L. acidophilus strain L1 secretes a non-bacteriocin antibacterial substance (s) active in vitro and in vivo. Appl. Environ. Microbiol., 63: 2747 - 2753.

- Champan, H. D. (1998): Evaluation of the efficacy of anticoccidial drugs against Eimeria sp. in the fowls. Int. J. parasitol. 28: 1141-1144.

- Conway,D.P.(1979):Examination of lesions and lesion scoring: 17-36 in (Poultry coccidiosis Diagnostic and Testing procedures). Pfizer, Int-ernational Inc. New York, USA.

- Conway, D. P.; Mathis, G. F.; Johnson, J. and Baldwin, C. (2003): The use of Diclazurilin extended withdrawal anticoccidial programs: 1. Efficacy against Eimeria species in broiler chickens in floor pens. Poultry Sci.,81: 349 - 352.

- Dalloul,R.A.; Liellehoj,H.S.; Shellem, T.A. and Doerr, J. A. (2003): Enhanced mucosal immunity against E. acervulina in broilers fed a Lactobacillus - based probiotic. Poult. Sci. 82: 62 - 66. 
- Dalloul,R.A.;Liellehoj,H.S.;Tamiim,N.; Shellem, T. and Doerr, J. (2005): Induction of local protective immunity to Eimeria acervulina by a Lactobacillus-based probiotic.Comp. Immunol. Microbiol. Infect. Dis., (5-6): 351-361

- Gusils, C.; Gonzalez, S. N. and Oliver, G. (1999): Some probiotic properties of chickens Lactobacilli. Can. J. Microbiol., 45: 981 - 987.

- Isolauri, E.; Sutas, Y.; Kankaanpaa, P.; Arulommi, $H$. and Salminen, S. (2001): Probiotics. Effects on immunity. Am. J. Clin. Nutr., 444S - 450S.

- Jin,L.Z.;Ho,Y.W.;Abdullah,N.;Ali,M. A. and Jalaudin, S. (1996): Antagonistic effects of intestinal Lactobacillus isolates on pathogens of chickens. Lett. Appl. Microbiol., 23: 67 - 71.

- Johnson,J.and Reid,W.M.(1970):Anti-coccidial drugs:lesion scoring techniques in battery and floor pen experiments with chickens. Exp. Parasitol., 28: 30 - 36.

- Kasper,H.(1998): Protection against gastrointestinal diseases. Present facts and future developments. Int. J. Food Microbiol., 41:127 - 131.

- Kawazone, U.and Fabio,J.D. (1994): Resistance to Diclazurilin field isolates of Eimeria sp. obtained from commercial broiler flocks in Brazil. Avian Pathol., 23: 305 311.

- Klasing, K. C.; Laurin, D. E.; Peng, R. K. and Fry, D. M. (1987): Immunologically mediated growth depression in chickens: Influence on feed intake, corticosterone and interleukin-1. Nut. Immunol., 117: 1629 - 1637.

- Liou,C.T.;Wang, J. S. and Ooi, H. K. (2001): Immunization against coccidiosis in pheasants with low-dose live sporulated oocysts of Eimeria colchici. Avian Pathol., 30: 283 - 295.

$\overline{\text { Kafr El-Sheikh Vet. Med. J. Vol. } 4 \text { No. } 1 \text { (2006) }}$ 
- Martin,A.;Maria,E.;Marta Cardazo;Angle,B.and Perez,P. (2005): Lactobacillus antagonize Giardia intestinalis in vivo. Infection and immunity, 73 (2): 1265 - 1269.

- McCracken, V. J. and Lorenz, R. G. (2001): The gastrointestinal ecosystem: a precarious alliance among epithelium, immunity and microbiota. Cell. Microbiol., 3: 1 11.

- Moshira El-Abasy; Maki Motobu; Kameo Shimura and Takashi Onodera (2004): Protective effects of sugar cane extracts (SCE) on E.tenella infection in chickens. J. Vet. Med. Sci., 6 (8): 865 - 671.

- Radwan, I. A. and Hassan, W. H. (2004): Competitive exclusion of Proteus mirabilis causing cloacal prolapse and embryonic chicken deaths.

- Reid,G.(1999): The scientific basis for probiotic strains of Lactobacillus. Appl. Environ. Microbiol., 65: 3763 - 3766.

- Samar S. Tawfik (1991): Effect of feeding regimes for broiler chicks on growth performance. M. V. Sc. Thesis, Fac. Vet. Med. Cairo Univ. Beni-Suef.

- Singer,S.M.and Nash,T.E.(2000): the role of normal flora in Giardia lamblia infections in mice. J. Infect. Dis., 181: 1510 1512.

- Soulsby, E. J. L. (1978): Helminthes, Arthropoda and Protozoa of domesticated Animals. $6^{\text {th }}$ ed. Bailliere and Tindall, London.

- Tierney, J.; Gowing, H.; Van Sinderen, D,; Flynn, S.; Stanley, L.; Mehardy,N.; Hallahan,S.and Mulcahy,G. (2004): In vitro inhibition of Eimeria tenella invasion by indigenious chickens Lactobacillus sp. Vet. Parasitol., 122 (3): 171 - 182.

- Upcroft, P. and Upcroft, J. (2001): Drug targets and mechanisms of resistance in the anaerobic protozoa.Clin. Microbiol.Rev.,14:150-164.

Kafr El-Sheikh Vet. Med. J. Vol. 4 No. 1 (2006) 
- Vaughan,E.E.; Mollet, B. and De Vos, W. M. (1999): Functionality of probiotic and intestinal lactobacilli:light in the intestinal tract tunnel. Curr. Opin. Biotechnol., 10: 505-510.

- Waters, W.R.;Harp,J.A.; Wannemuchler,M.J.;Carbajal,N. Y. and Casas,I.A.(1999): Effect of Lactobacillus reuteri on Cryptosporidium parvum infection of gnobiotic TCR-alphadeficient mice. J. Eukaryot. Microbiol., 46: 60 S - 61 S.

- Yun, C. H.; Lillehoj, H. S. and Choi, K.D. (2000): Eimeria tenella infection induces local $\gamma$-interferon production and intestinal lymphocyte subpopulation changes. Infect. Immun., 68: $1282-1288$. 